\title{
Protonated Carbon Nitride Incorporated Polyamide Thin Film Nanocomposite for Reverse Osmosis Desalination
}

\author{
A. Abdul Aziz, P. S. Goh*, M. A. Azali, M. N. Zainal Abidin \& M. H. Abu Ba'dah \\ School of Chemical and Energy Engineering, Faculty of Engineering, Universiti \\ Teknologi Malaysia, 81310 UTM Johor Bahru, Johor, Malaysia
}

Submitted: 25/2/2019. Revised edition: 10/3/2019. Accepted: 13/03/2019. Available online: 15/7/2019

\begin{abstract}
Protonated carbon nitride $(\mathrm{pCN})$ prepared from acid treatment of carbon nitride $(\mathrm{CN})$ was incorporated in the polysulfone (PSf) substrate and polyamide (PA) layer to produce thin film nanocomposite (TFN) membrane. The hydrophilicity of $\mathrm{CN}$ is expected to improve the surface hydrophilicity of the membrane and acid treatment of nanoparticle is aimed to further enhance the surface structure and prevent the agglomeration of nanomaterial from taking place. pCN loading used in the PSf substrate was $0.5 \%$ while in the PA layer was varied as $0.05 \%, 0.1 \%$ and $0.15 \%$. All the membrane prepared were characterized in terms of morphology, structural properties, and surface chemistry. Reverse osmosis dead-end filtration system was used to determine the water permeability and the salt rejection. It was observed that, all the membrane prepared could maintain the salt rejection with improvement of water permeability. However, the salt rejection was sacrificed when higher loading of $0.15 \% \mathrm{pCN}$ was tested, although the water permeability of the membrane has reached approximately 0.5 LMHbar. This work demonstrates that the use of $\mathrm{pCN}$ in $\mathrm{RO}$ membrane can improve the water permeability without sacrificing the salt rejection.
\end{abstract}

Keywords: Thin film nanocomposite, carbon nitride, protonated carbon nitride, reverse osmosis, surface modification

\subsection{INTRODUCTION}

World human populations facing a growth rate of $1.2 \%$ per year and is expected to reach up to 14.4 billion peoples in less than 60 years [1]. With the exponential growth of world population, current resources should be taken care of to ensure their sustainability in more generations to come. Fresh water supply is undoubtedly the most vital resource for human life. Source of fresh water should not be taken for granted many parts of the world populations are already lost their supplied for a fresh water. According to United Nations World Water
Development Report 2015, there are still 748 million peoples lacking of access to the fresh water supply and the demand for fresh water is estimated to be increased by 400 percent globally by 2050 [2].

Reverse osmosis (RO) is a promising technology in purifying seawater or salt water into a drinking water. It is one of the most reliable techniques to increase the production of fresh water supply among the various existing method. This concept was introduced by Loeb and Sourirajan that included the process of demineralization of the salt water, preparation of the membrane and overall process of RO [3]. In RO process, thin 
film composite (TFC) membrane was usually used as a medium to obtain fresh water. TFC membrane comprises of a thin film or polyamide (PA) layer act as a selectivity layer produced from the interfacial polymerization from the reaction between two monomers on top of a porous support membrane [4]. An ideal TFC membranes should possess several key characteristics such as high salt rejection $(>98 \%)$, high water permeability, excellent mechanical strength and anti-fouling properties.

As a new technology evolved, research on membrane field was also developed to expand their capability and performances. The introduction of nanomaterials is a promising way to address the limitations of TFC membrane such as low water permeability and fouling by introducing the usage of nanofillers in the membrane fabricated either in the support membrane called mixed matrix membrane (MMM) or in a PA layer called thin film nanocomposite (TFN) [5]. By introducing nanomaterials within the membrane, membrane characteristics such as mechanical strength and chemical stability as well as salt separation and water permeability could be greatly improved [6]. In this work, protonated carbon nitride ( $\mathrm{pCN}$ ) was embedded in the support membrane and PA layer, respectively. This intention of the current study was to improve the water permeability performances of the membrane without compromising the salt rejection. Wang et al. have evidenced that [7], $\mathrm{CN}$ was capable to improve the wettability of the membranes thus improve the hydrophilicity and water permeability. This happen due to the formation of hydrogen bond that present between nitrogen atom of the $\mathrm{CN}$ with water molecule. On the other hand, works reported by Wan Azelee et al. [8] who treated their hybrid nanomaterial of multiwalled carbon nanotube and titania nanotube (MWCNT-TNT) with strong acid to positive surface charge have effectively improved the dispersion of nanomaterials in the solutions. Furthermore, the positively charged surface of substrate also positively affected the formation of PA layer, hence resulted in enhanced flux and salt rejection. In this work, $\mathrm{pCN}$ was used as nanofillers in the substrate and PA layer to create a positive charge on active layer and thin film so that PA layer would have a stronger attraction within the PSf support layer.

\subsection{METHODS}

\subsection{Materials}

Polysulfone Udels P-3500 polymer, supplied in a form of a pellet by Solvay, polyvinylpyrrolidone (PVP, K29-32) and 1-methyl-2-pyrrolidinone (NMP,99.5\%) was obtained from Acros Organic were used to develop support membrane. mPhenylenediamine (MPD,99\%) and 1,3,5-benzenetricarbonyl trichloride (TMC,98\%) from Acros Organic were used to prepare PA layer (i.e., using PSf as supports). Sodium chloride $(\mathrm{NaCl}$, 99.5\%) provided by ACL Labscan and nhexane $\left(\mathrm{C}_{6} \mathrm{H}_{6}, 49 \%\right)$ were supplied by Merck, while hydrochloric acid $(\mathrm{HCl}$, $65 \mathrm{wt} \%$ ) was obtained from Merck. Melamine was supplied by SigmaAldrich.

\subsection{Synthesis of Carbon Nitride and Acid Treatment}

Melamine was used to fabricate $\mathrm{CN}$ through a thermal polycondensation method. In a typical procedure, $10 \mathrm{~g}$ of 
melamine powder was place into a crucible with a lid and then covered the whole crucible with an aluminium foil to prevent from sublimation to happen [9]. Then, the crucible was heated in air condition by a carbolite furnace at $550{ }^{\circ} \mathrm{C}$ for $2 \mathrm{~h}$ with a heating rate of $5{ }^{\circ} \mathrm{C} / \mathrm{min}$. After it was cooled to room temperature, the yellow product was collected and ground into a powder with a ceramic mortar. For pCN, $50 \mathrm{~mL}$ of $5 \mathrm{M}$ hydrochloric acid was mixed with 5 grams of $\mathrm{CN}$ used. The solution was then stirred overnight, followed by filtration and washing with deionised water until $\mathrm{pH}$ become neutral. Lastly, the nanoparticles were dried at $100^{\circ} \mathrm{C}$ under vacuum.

\subsection{Preparation of Polysulfone (PSf) Support Membrane}

Phase inversion technique was used to fabricate PSf substrate. The casting solution to produce neat PSf substrates was prepared by dissolving $17.5 \mathrm{wt} \% \mathrm{PSf}$ in a solvent NMP with $0.5 \mathrm{wt} \%$ of PVP. $0.5 \mathrm{wt} \%$ of $\mathrm{pCN}$ was added in the casting dope solution to prepare PSf substrate that was incorporated with $\mathrm{pCN}$. The dope solution was stirred for $24 \mathrm{~h}$ to ensure a good dispersion of $\mathrm{pCN}$. After that, the dope solution was left for sonication in room temperature for 1 to 2 $\mathrm{h}$ before proceed to casting to eliminate the air bubbles. The dope solution was then cast onto a clean glass plate using a glass rod and then immersed directly into the coagulation bath containing deionised water. The same procedure was used to prepare neat substrate but without the addition of $\mathrm{pCN}$ into the dope solution.

\subsection{Preparation of Thin Film Composite and Thin Film Nanocomposite Membranes}

PA active layer was prepared by interfacial polymerization method. $2 \%$ of MPD in deionised water and $0.1 \%$ TMC in n-hexane were used as monomers to form the PA layer on the top of the support membrane. Active layer of the support membrane was placed between a glass plate and the rubber frame and poured the MPD solution. After $1 \mathrm{~min}$, excess MPD solution was drained off and removed the leftover by a rubber roller. Then, TMC solution was dripped on the surface to react with MPD for 50 second. After that, excess TMC solution was poured out and let it dry in ambient temperature for $1 \mathrm{~min}$. The membranes were post-treated in an oven at $60^{\circ} \mathrm{C}$ for $5 \mathrm{~min}$ and later stored in DI water for 24 hours before further use.

For TFN membrane, $0.05 \mathrm{w} / \mathrm{v} \%, 0.1$ $\mathrm{w} / \mathrm{v} \%$ and $0.15 \mathrm{w} / \mathrm{v} \%$ of $\mathrm{pCN}$ were mixed with the TMC solution. The mixture was then sonicated for $1 \mathrm{~h}$ prior to interfacial polymerization to avoid agglomeration of the nanoparticles. The denotations of the TFN membranes prepared in this study are tabulated in Table 1. 
Table 1 Denotation use to represent the membranes

\begin{tabular}{lcc}
\hline \multicolumn{1}{c}{$\begin{array}{c}\text { Substrate/ support } \\
\text { membrane }\end{array}$} & PA layer & Denotation \\
\hline $17.5 \mathrm{wt} \% \mathrm{PSf}+0.5 \mathrm{wt} \%$ & MPD $+\mathrm{TMC}$ & $\mathrm{TFC}$ \\
$\mathrm{PVP}$ & $\mathrm{MPD}+\mathrm{TMC}$ & $\mathrm{pCN}-\mathrm{TFN}$ \\
$17.5 \mathrm{wt} \% \mathrm{PSf}+0.5 \mathrm{wt} \%$ & & $0.05 \mathrm{pCN}-\mathrm{pCN}-\mathrm{TFN}$ \\
$\mathrm{PVP}+0.5 \mathrm{wt} \% \mathrm{pCN}$ & & \\
$17.5 \mathrm{wt} \% \mathrm{PSf}+0.5 \mathrm{wt} \%$ & $\mathrm{MPD}+\mathrm{TMC}(0.05 \mathrm{w} / \mathrm{v} \% \mathrm{pCN})$ & $0.1 \mathrm{pCN}-\mathrm{pCN}-\mathrm{TFN}$ \\
$\mathrm{PVP}+0.5 \mathrm{wt} \% \mathrm{pCN}$ & & \\
$17.5 \mathrm{wt} \% \mathrm{PSf}+0.5 \mathrm{wt} \%$ & $\mathrm{MPD}+\mathrm{TMC}(0.1 \mathrm{w} / \mathrm{v} \% \mathrm{pCN})$ & $0.15 \mathrm{pCN}-\mathrm{pCN}-\mathrm{TFN}$ \\
$\mathrm{PVP}+0.5 \mathrm{wt} \% \mathrm{pCN}$ & & \\
$17.5 \mathrm{wt} \% \mathrm{PSf}+0.5 \mathrm{wt} \%$ & $\mathrm{MPD}+\mathrm{TMC}(0.15 \mathrm{w} / \mathrm{v} \% \mathrm{pCN})$ & \\
$\mathrm{PVP}+0.5 \mathrm{wt} \% \mathrm{pCN}$ & &
\end{tabular}

\subsection{Characterization of Nanomaterials and Membranes}

Morphology of $\mathrm{CN}$ and $\mathrm{pCN}$ was analysed by using transmission electron microscopy (TEM, HT 770, Hitachi, Japan). X-ray diffraction (XRD, $\mathrm{Cu} \mathrm{Ka}$ radiation, $\lambda=0.154 \mathrm{~nm}, \mathrm{D} / \max -\mathrm{rB} 12 \mathrm{~kW}$ Rigaku) was used to examine the crystallinity of the $\mathrm{CN}$ and $\mathrm{pCN}$. Other than that, attenuated total reflectance fourier transmission infrared spectroscopy (ATR-FTIR, Thermo Nicolet Avatar 360) was used to identify the functional groups of the nanomaterials and the membranes prepared. To investigate the morphological structure of the membrane, field emission scanning electronic microscope (FESEM, SU8020, Hitachi) was used to have a highresolution image and energy-dispersive $\mathrm{X}$-ray spectroscopy (EDX) to analyse the element on the samples. Membrane surface charge was determined by zeta potential test (Malvern Zetasizer Nano ZS). Lastly, surface roughness $\left(R_{a}\right)$ was measured by using atomic force microscopy (AFM, SII Nano Technology SPA $300 \mathrm{HV}$ ) and the wettability of the membrane was examined using contact angle goniometer (OCA 15 Pro, Dataphysics).

\subsection{Evaluation of Membrane Performances}

Dead-end filtration system was used to measure RO performance that was made of stainless steel 316 (Model HP4750 Stirred Cell, Sterlitech Corp., Kent, WA). The membrane contact surface area was $14.6 \mathrm{~cm}^{2}\left(2.26 \mathrm{in}^{2}\right)$. Firstly, the membrane was stabilized at 16 bar for $30 \mathrm{~min}$ with RO water to compact the structure of the membrane and then was reduced to 15 bar for further used. Next, $\mathrm{NaCl}$ solution (2000 ppm) was used as feed water and permeated water was collected. The water permeability $(A)$ and salt rejection $(\mathrm{R})$ were determined. The water permeability was calculated based the equation:

$A$ (LMHbar) $=\frac{V}{A t \Delta P}$

where $\mathrm{V}$ is volume of permeate water in the experiment, $\mathrm{A}$ is the area of membrane, and $t$ is the time of permeate water. While salt rejection was determined by using the equation:

$\mathrm{R}(\%)=(1-C p / C f) x 100$ 
where $C_{p}$ is the concentration of permeate solution and $\mathrm{C}_{\mathrm{f}}$ is the feed solution concentration.

\subsection{RESULT AND DISCUSSIONS}

\subsection{Characterizations of $\mathrm{CN}$ and $\mathrm{pCN}$}

Figure 1 shows the morphological structure of $\mathrm{CN}$ and $\mathrm{pCN}$ obtained from TEM characterization. As can be seen, the morphology of both nanomaterials is with nanosheet graphene-like structure. This observation has been reported by $\mathrm{M}$. Sihor et al. [10] and J. Zhu et al. [11]. The difference between both nanomaterials was the stacking of nanosheet after the modification using strong acid. The modified $\mathrm{CN}$ has created high repulsive forces between the molecular structure by absorbing the positive charge carried by $\mathrm{H}^{+}$in $\mathrm{HCl}$ thus increase the distance between the sheets. Figure 2 shows the chemical bonding of $\mathrm{CN}$ and $\mathrm{pCN}$. The thermal condensation of melamine will be produced carbon nitride through deamination and formed tri-s-triazine (proved through ATR-FTIR testing on Figure 3). The hydrochloric acid treatment has modified the chemical structure of the carbon nitride by adsorption of hydrogen ion on the nanomaterials surface. This was also stated by Mudunkotuwa et al. [12] who modified $\mathrm{TiO}_{2}$ using adsorption of citric acid with $\mathrm{pH}$ range of 2.0, 4.0, 6.0 and 7.5. Higher repulsive forces were experienced by $\mathrm{TiO}_{2}$ after protonation and increasing of $\mathrm{pH}$ solution to acidic could bring the nanomaterials to positively charge. This phenomena can be explained by Derjaguin, Landau, Verwey, and Overbeek theory (DLVO theory) where electrostatic repulsion would increase and the Van Der Waals attraction forces become low when the distances of charged nanosheets increase [13]. By measuring the particles size based on the TEM results, $\mathrm{CN}$ possessed an average particle size of $28.96 \mathrm{~nm}$ and pCN showed approximately of $37.47 \mathrm{~nm}$
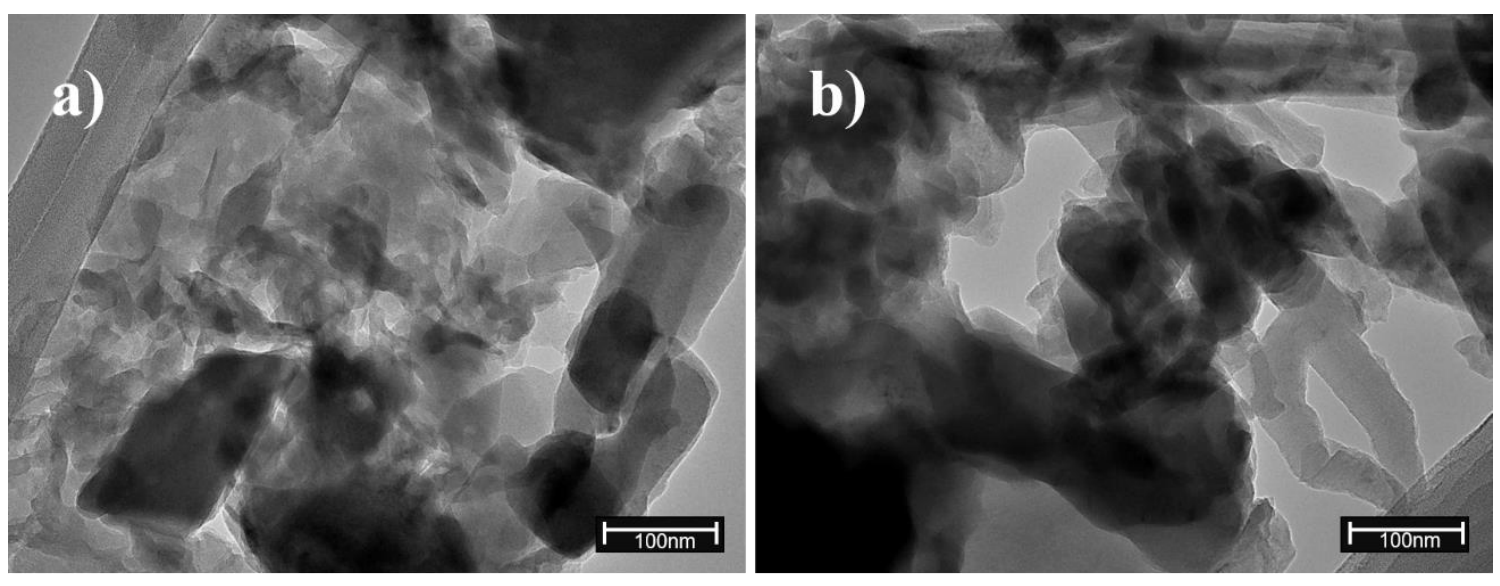

Figure 1 TEM image of a) $\mathrm{CN}$ and b) pCN

The ATR-FTIR spectra of $\mathrm{CN}$ and $\mathrm{pCN}$ are shown in Figure 3. The peak present at wavenumber $802 \mathrm{~cm}^{-1}$ represents the s-triazine ring unit [15].
While the peaks exist between $1200 \mathrm{~cm}^{-1}$ to $1650 \mathrm{~cm}^{-1}$ related to the $\mathrm{C}-\mathrm{N}$ heterocycles skeleton stretching. Peaks on 1243, 1322, 1461, and $1623 \mathrm{~cm}^{-1}$ 
derived from trigonal C-N(-C)-C (full condensation) and $\mathrm{C}-\mathrm{NH}-\mathrm{C}$ units (partial condensation) [16]. Then, peaks present between $3000 \mathrm{~cm}^{-1}$ to $3700 \mathrm{~cm}^{-1}$ (3104 $\mathrm{cm}^{-1}, 3278 \mathrm{~cm}^{-1}, 3411 \mathrm{~cm}^{-1}$ ) were representing stretches of $\mathrm{N}-\mathrm{H}$ and $\mathrm{O}-\mathrm{H}$ due to the adsorbed of hydroxyl and free amino groups [17]. All of this characteristic peak present in both nanomaterials shown that $\mathrm{pCN}$ and $\mathrm{CN}$ were almost identical to each other.

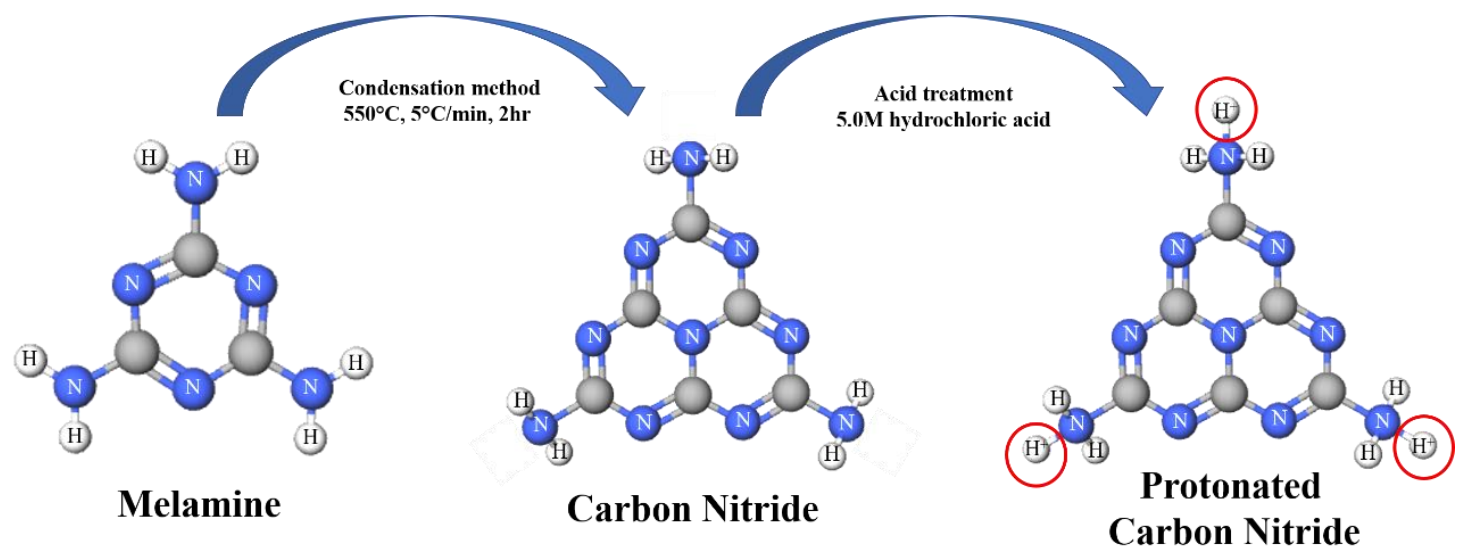

Figure 2 The schematic diagram that shows the formation of $\mathrm{CN}$ and $\mathrm{pCN}$ [14]

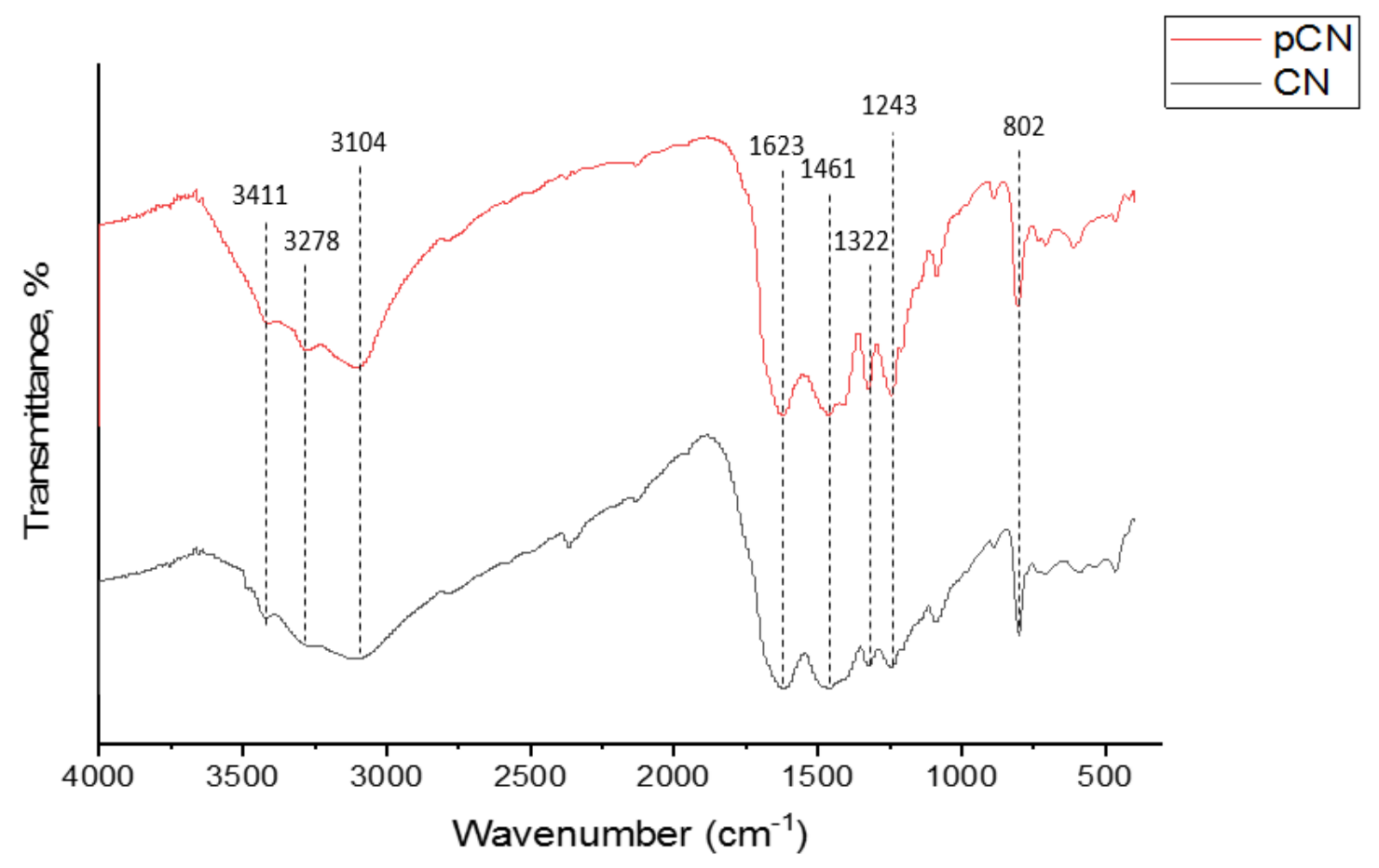

Figure 3 ATR-FTIR spectra of $\mathrm{pCN}$ and $\mathrm{CN}$ 
Figure 4 presents the XRD patterns of CN and $\mathrm{pCN}$. It can be seen that both of the nanomaterials still have 2 characteristic peaks even after being treated with acid. First peak that exist at 2-theta approximately $28.0^{\circ}$ presenting the characteristic (002) interlayer-stacking distance (d-spacing) of $\mathrm{CN}$ that shown a graphene-like structure [18]. Upon protonation of $\mathrm{CN}$, shifting of the peak was observed from $28.0^{\circ}(\mathrm{d}=0.318 \mathrm{~nm})$ to $27.42^{\circ}(\mathrm{d}=0.325 \mathrm{~nm})$. This means that d-spacing of planar graphitic structure of
$\mathrm{CN}$ was increased throughout the protonation process due to the existence of positive charge on the surface of the nanosheet [19, 20]. Another peak that present on approximately $12.48^{\circ}$ was showing the structure of repeated striazine unit as shown in Figure 2. The same peak was observed by Niu et al. that fabricated $\mathrm{CN}$ through the same precursor with 4 hour durations [21]. By treating $\mathrm{CN}$ with strong acid like $\mathrm{HCl}$, structure of repeated s-triazine was not affected [17].

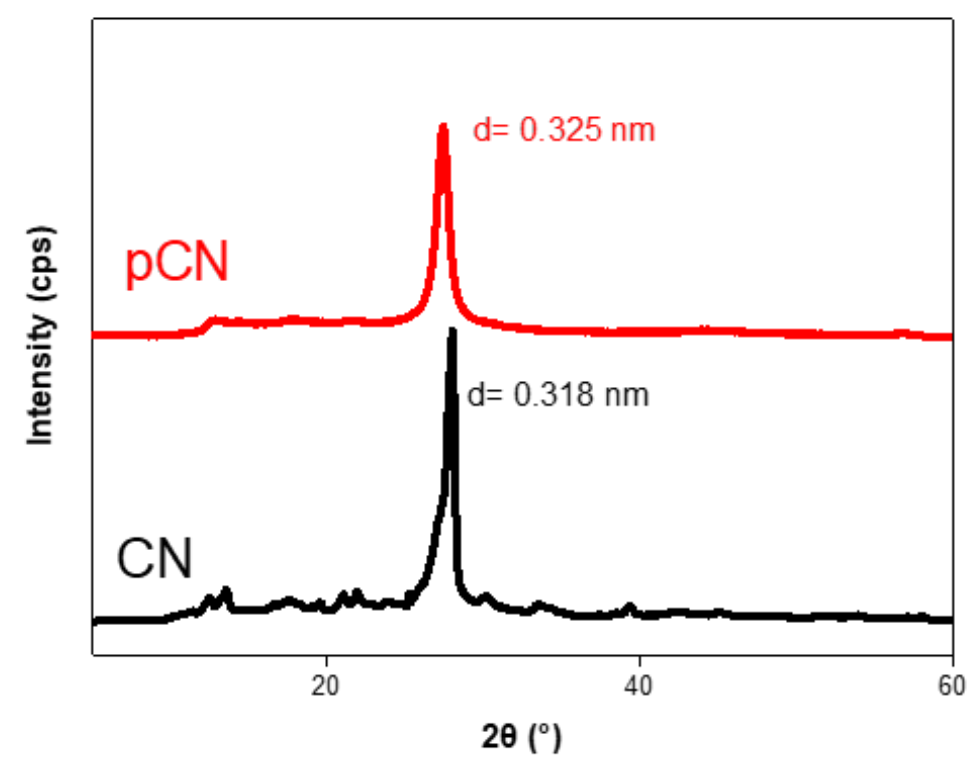

Figure $4 \mathrm{XRD}$ pattern of $\mathrm{CN}$ and $\mathrm{pCN}$

\subsection{Characterization of Membrane}

The membrane surface and crosssectional morphology is illustrated in Figure 5. Figure $5 \mathrm{~A}$ and $5 \mathrm{~B}$ show the surface of PA layer on top of the PSf support membrane. Both of this membrane surface was showing a typical 'leaf-like' outgrowths and 'ridge-andvalley' structure that can be observed in any membrane with coating of a thin PA layer [22]. No noticeable difference in the morphology was observed since the membranes were not embedded with any nanoparticles. The difference can be figure out on Figure 5C, 5D and 5E. Spot of the pCN nanoparticle can be seen and aggregation of nanoparticles were spotted when $0.15 \%$ loading of $\mathrm{pCN}$ was used in the PA layer. The cross-sectional images of TFC and TFN membrane prepared that consist of PA thin film layer and PSf substrate are shown in Figure 5 (a-e). From the cross-sectional images of the membrane, finger-like structure was observed. This type of structure were also observed by others work that applied the same dope formulation [23-25]. 


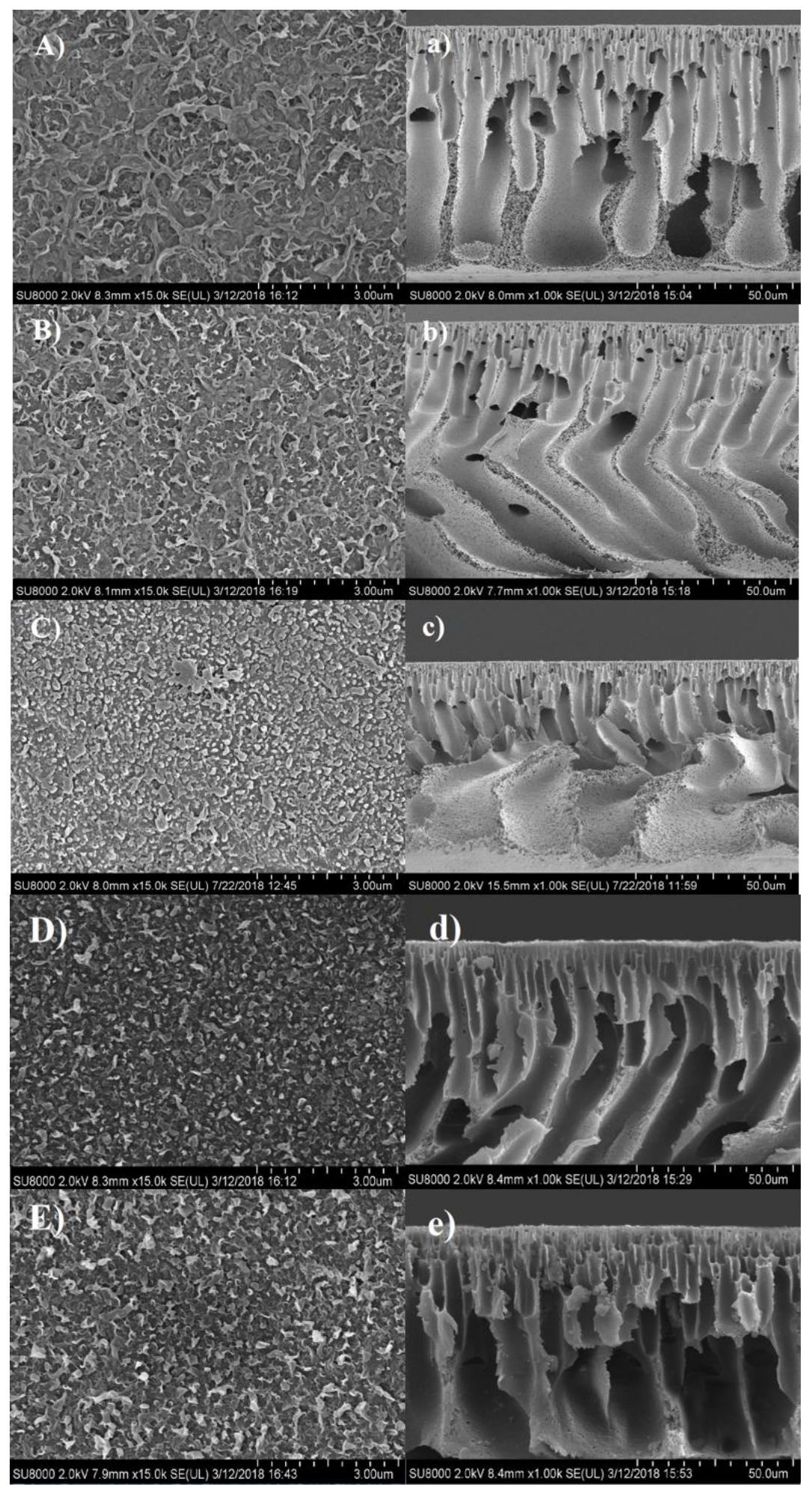

Figure 5 Surface (A-E) and cross section (a-e) FESEM image of TFC, pCN-TFN, 0.05 pCN-pCN-TFN, $0.1 \mathrm{pCN}-\mathrm{pCN}-\mathrm{TFN}$, and $0.15 \mathrm{pCN}-\mathrm{pCN}-\mathrm{TFN}$, respectively 
Due to the low loading of $\mathrm{pCN}$ used in the PSf support membrane, cross sectional images did not show visible $\mathrm{pCN}$ nanoparticles. However, the existence of $\mathrm{pCN}$ in the substrate was evidenced with
EDX elemental analysis as shown in Figure 6. It can be seen that $\mathrm{pCN}$ embedment increased the carbon and nitrogen composition because of it is the main element.
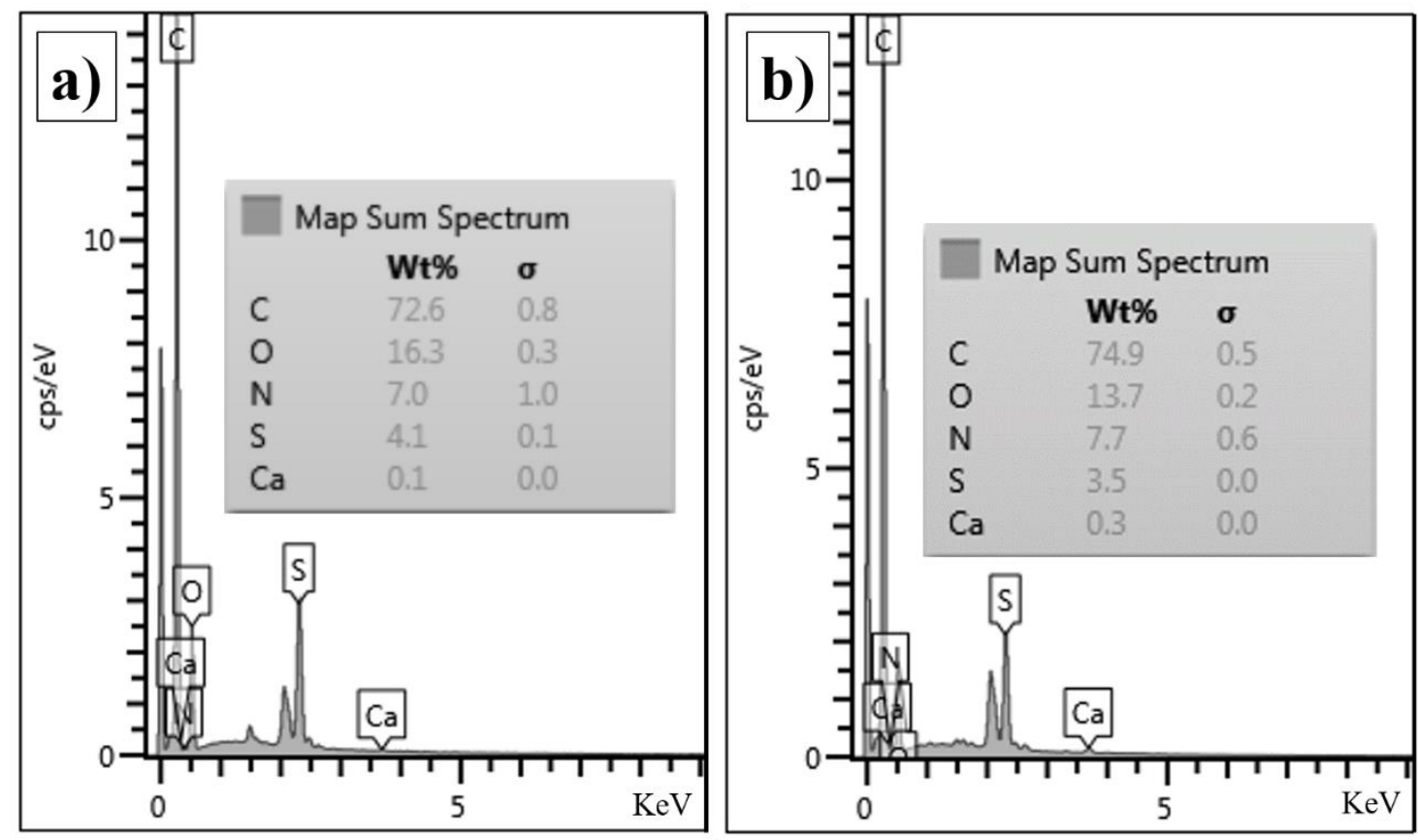

Figure 6 EDX elemental analysis (a) TFC and (b) pCN-TFN

Figure 7 shows three-dimensional AFM images of the membranes with their average value of surface roughness $(\mathrm{Ra})$. Surface roughness of the TFN membrane was influenced by PA layer that showed a ridge-and-valley structure which caused by the polymerized film of amine and acyl chloride monomers $[8,26]$. Figure $7 \mathrm{a}$ shows $\mathrm{Ra}=34.71 \mathrm{~nm}$ for typical TFC membrane. While, the pCN-TFN membrane showed $35.37 \mathrm{~nm}$ for surface roughness since the embedded $\mathrm{pCN}$ within PSf support would increase the surface area [27]. This trend was also observed by Lai et al. [28] who used various loadings of graphene oxide (GO) to increase the surface roughness of the membrane. With embedding $\mathrm{pCN}$ on $\mathrm{PA}$ layer, the surface roughness is increase with increasing loading of $\mathrm{pCN}$. Figure $7 \mathrm{c}$ showed the surface roughness increases to $36.35 \mathrm{~nm}$ when $0.05 \%$ of pCN were embedded on PA layer. This surface roughness values rapidly increase when higher loading of $\mathrm{pCN}$ were used to embedded pCN inside of the PA layer. Membrane 0.1 pCN-pCN-TFN (Figure 7d) and 0.15 pCN-pCN-TFN (Figure 7e) was showing $41.9 \mathrm{~nm}$ and $42.03 \mathrm{~nm}$, respectively.

Table 2 recorded the contact angle and surface charge value of the prepared membranes. The contact angle measurement was used to determine the surface wettability of the membranes. The contact angles of TFC showed the highest value among the prepared membranes. TFC showed the contact 
angle value of $88.92^{\circ} \pm 3.24$ and decrease to $76.11^{\circ} \pm 3.33$ after embedded of $\mathrm{pCN}$ inside the substrate. This due to the higher surface area produces when it has high surface roughness (shown in Figure 7). The same observation has been made by M. Rezaei-DashtArzhandi et al. [29] who used various loadings of $\mathrm{CN}$. They reported that the contact angle decreased with increasing loading of nanoparticles. The surface charge was analysed by using zeta potential. TFC membranes exhibited surface charge value of $-47.3 \mathrm{mV}$. The pCN-TFN surface charge value was slightly increased to $-35.7 \mathrm{mV}$. This increase might be caused by the positive charge that carried by $\mathrm{pCN}$ in the substrate. This increment was observed when loadings of $\mathrm{pCN}$ were embedded in the PA layer. Surface charge for the membrane 0.05 pCN-pCN-TFN, 0.1 pCN-pCN-TFN and 0.15 pCN-pCN-TFN were showed about $-28.2,-18.6$ and 5.76 , respectively. This negative charge surface on the membrane surface was needed to expel negative ion such as $(\mathrm{Cl})$ hence preventing the ions from pass through the membrane [30].
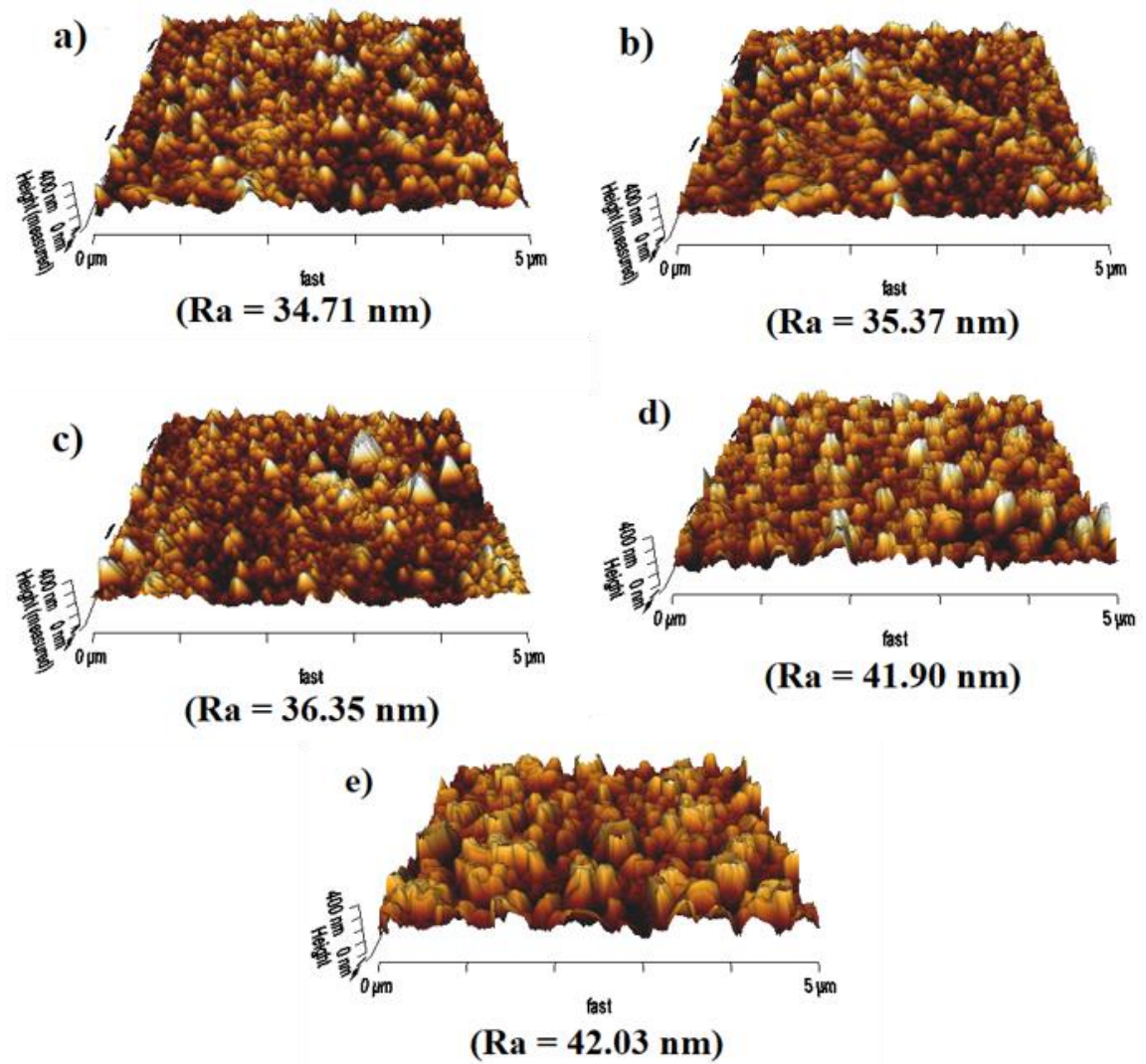

Figure 7 AFM images of (a) TFC, (b) pCN-TFN (c) 0.05 pCN-pCN-TFN, (d) 0.1 pCN-pCNTFN, and (e) 0.15 pCN-pCN-TFN 
Table 2 Surface charge and contact angle of TFC and TFN membrane

\begin{tabular}{lcc}
\hline Membrane types & Contact angle $\left(^{\circ}\right)$ & Surface charge $(\mathbf{m V})$ \\
\hline TFC & $88.92 \pm 3.24$ & -47.3 \\
pCN-TFN & $76.11 \pm 3.33$ & -35.7 \\
0.05 pCN-pCN-TFN & $59.74 \pm 3.19$ & -28.2 \\
0.1 pCN-pCN-TFN & $57.39 \pm 2.42$ & -18.6 \\
0.15 pCN-pCN-TFN & $52.61 \pm 2.67$ & -5.76 \\
\hline
\end{tabular}

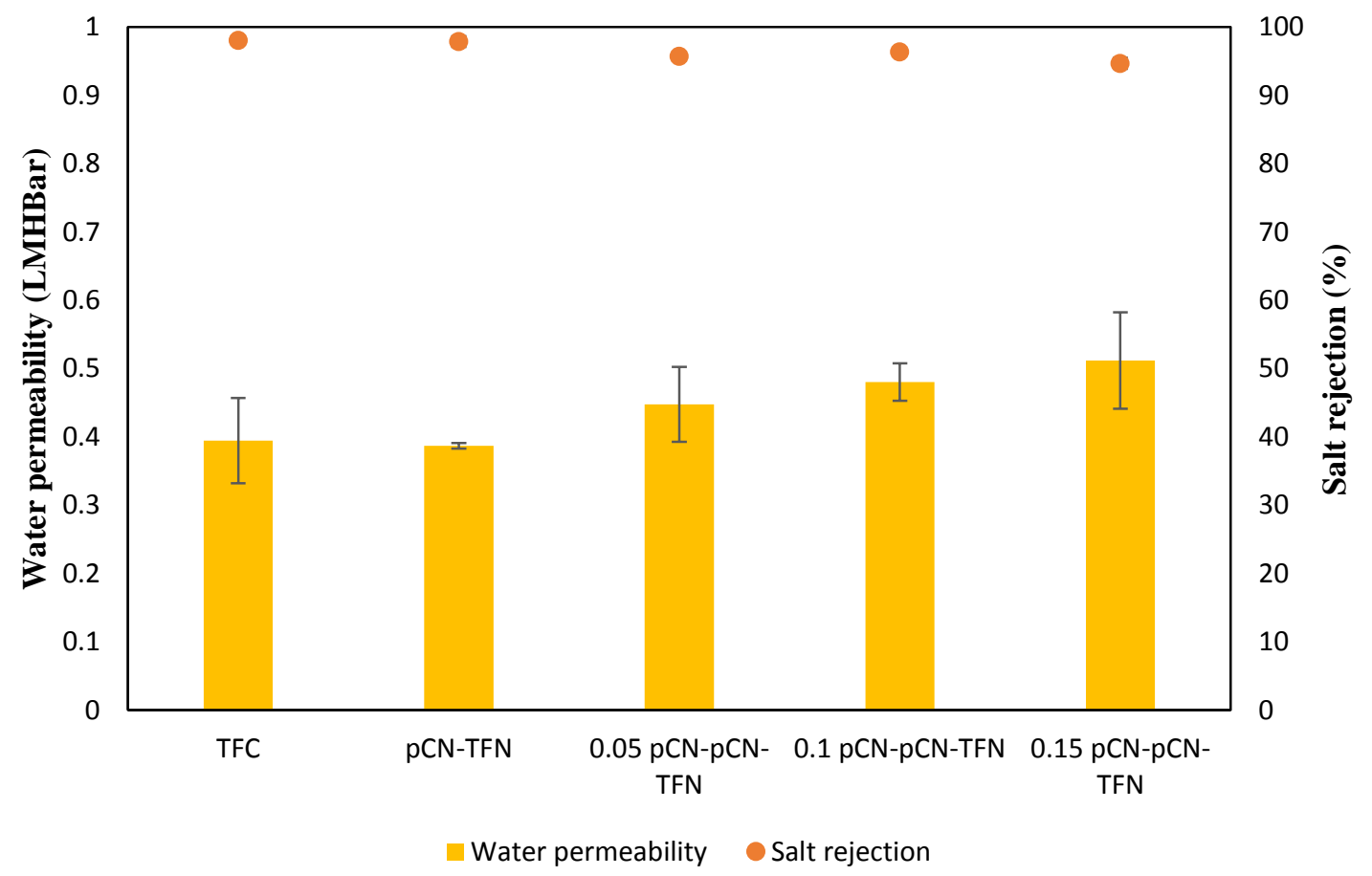

Figure 8 Water permeability and salt rejection of TFC and TFN membranes (test condition: 15 bar, $25^{\circ} \mathrm{C}, 2000 \mathrm{ppm} \mathrm{NaCl}$ solution)

\subsection{RO Performance}

Water permeability and salt rejection performances of the membrane were illustrated in Figure 7. Based on the figure, the result of TFC and pCN-TFN membrane showed no significant different that can be measure. TFC membrane shows $0.39 \mathrm{LMHbar}$ of water permeability with $98.0 \% \mathrm{NaCl}$ rejection while pCN-TFN shows 0.38 LMHbar and
$97.9 \%$, respectively. The water permeability of the membrane was increased when loadings of $\mathrm{pCN}$ were embedded in the PA layer. The highest water permeability achieved was 0.15 pCN-pCN-TFN membrane with 0.51 LMHbar. Even though the water permeability was increased with higher loading of $\mathrm{pCN}$, the salt rejection was compromised. The result shown that 0.15 pCN-pCN-TFN membrane has sacrifice 
the salt rejection and dropped to $94.7 \%$. This could happen due to the agglomeration of the nanoparticle thus affecting the formation of PA layer on top of the PSf support membrane. This trend has also been reported by Ma et al. [31] who used up to $0.2 \%$ loading of zeolite as nanofiller in the PA layer. They observed the decrement of salt rejection although the water permeability was increased.

\subsection{CONCLUSION}

In this work, $\mathrm{pCN}$ was obtained from the acid treatment of $\mathrm{CN}$ to alter its surface charge from negative to positive. The intention of embedding $\mathrm{pCN}$ within the PSf substrate was to increase the interaction between the PSf substrate and the PA layer where the PA layer can be strongly attached on the active layer of the substrate. Besides that, the desired properties of $\mathrm{pCN}$ in terms of high hydrophilicity have also positively affected the overall properties of the TFN. The samples prepared in this work, i.e. 0.05 pCN-pCN-TFN, 0.1 pCN-pCN-TFN and 0.15 pCN-pCN-TFN could significantly maintain the salt rejection while improving the water permeability. As a conclusion, this work gives an insight into the potential of applying $\mathrm{pCN}$ in modifying the structure and physicochemical properties of the resultant TFN membranes, hence improving the desalination performance.

\section{ACKNOWLEDGEMENT}

The authors would like to acknowledge the financial supports provided by Ministry of Higher Education Malaysia under HiCOE Grants (4J182 and 4J196) and Universiti Teknologi Malaysia under Research University Grant (18H35).

\section{REFERENCES}

[1] D. Pimentel, M. Burgess. 2015. World Human Population Problems. Reference Module in Earth Systems and Environmental Sciences. Elsevier Inc. 4: 313-317.

[2] WWAP (United Nations World Water Assessment Programme). 2015. The United Nations World Water Development Report 2015: Water for a Sustainable World. Paris, UNESCO.

[3] D. E. W. S. Loeb, S. Sourirajan. 1964. High Flow Porous Membranes for Separating Water from Saline Solutions.

[4] V. Vatanpour, M. Safarpour, A. Khataee, H. Zarrabi. 2017. A Thin Film Nanocomposite Reverse Osmosis Membrane Containing Amine-functionalized Carbon Nanotubes. Separation and Purification Technology. 184: 135143.

[5] D. Emadzadeh, W. J. Lau, M. Rahbari-sisakht, A. Daneshfar, M. Ghanbari, A. Mayahi. 2015. A Novel Thin Film Nanocomposite Reverse Osmosis Membrane with Superior Anti-organic Fouling Affinity for Water Desalination. DES. 368: 106-113.

[6] J. Farahbaksh, M. Delnavaz, V. Vatanpour. 2017. Investigation of Raw and Oxidized Multiwalled Carbon Nanotubes in Fabrication of Reverse Osmosis Polyamide Membranes for Improvement in Desalination and Antifouling Properties. Desalination. 410: 1-9.

[7] Y. Wang, R. Ou, H. Wang, T. Xu. 2015. Graphene Oxide Modified Graphitic Carbon Nitride as a Modifier for Thin Film Composite Forward Osmosis Membrane. $J$. 
Membr. Sci. 475: 281-289.

[8] I. W. Azelee, P. S. Goh, W. J. Lau, A. F. Ismail, K. C. Wong, M. N. Subramaniam. 2017. Enhanced Desalination of Polyamide Thin Film Nanocomposite Incorporated with Acid Treated Multiwalled Carbon Nanotube-titania Nanotube Hybrid. Desalination. 409: 163170.

[9] S. C. Yan, Z. S. Li, Z. G. Zou. 2009. Photodegradation Performance of g-C3N4 Fabricated by Directly Heating Melamine. Langmuir. 25: 10397-10401

[10] M. Sihor, P. Praus, L. Svoboda, M. Ritz, I. Troppov, K. Ko. 2017. Graphitic Carbon Nitride: Synthesis, Characterization and Photocatalytic Decomposition of Nitrous Oxide, Materials Chemistry and Physics. 193: 438446.

[11] J. Zhu, P. Xiao, H. Li, A. C. Carabineiro. 2014. Graphitic Carbon Nitride: Synthesis, Properties, and Applications in Catalysis. Applied Materials and Interfaces. 6: 16449-16465.

[12] I. A. Mudunkotuwa, V. H. Grassian, 2010. Citric Acid Adsorption on $\mathrm{TiO} 2$ Nanoparticles in Aqueous Suspensions at Acidic and Circumneutral Ph: Surface Coverage, Surface Speciation, and Its Impact on Nanoparticle Nanoparticle Interactions. J. Am. Chem. Soc. 132: 14986-14994.

[13] B. W. Ninham. 1999. On Progress in Forces Since the DLVO Theory, Advances in Colloid and Interface Science. 83: 1-17.

[14] W. Ong, L. Tan, S. Chai, S. Yong, A. Rahman. 2015. Surface Charge Modification via Protonation of Graphitic Carbon Nitride (g-C3N4) for Electrostatic Self-assembly Construction of 2D / 2D Reduced Graphene Oxide (rGO)/g-C3N4 Nanostructures Toward Enhanced Photocatalytic Reduction of Carbon Dioxide to Metha. Nano Energy. 13: 757-770.

[15] L. Ma, H. Fan, K. Fu, S. Lei, Q. Hu, H. Huang, G. He. 2017. Protonation of Graphitic Carbon Nitride (gC3N4) for Electrostatically Selfassembling Carbon @ g-C3N4 Core-shell Nanostructure Toward High Hydrogen Evolution. Sustainable Chemistry and Engineering. 5: 7093-7103.

[16] X. Zhang, J. Hu, H. Jiang. 2014. Facile Modification of a Graphitic Carbon Nitride Catalyst to Improve Its Photoreactivity Under Visible Light Irradiation. Chemical Engineering Journal. 256: 230237.

[17] W. Ong, L. Tan, S. Chai, S. Yong, A. Rahman. 2015. Surface Charge Modification via Protonation of Graphitic Carbon Nitride (g-C3N4) for Electrostatic Self-assembly Construction of 2D / 2D Reduced Graphene Oxide (rGO)/ g-C3N4 Nanostructures toward Enhanced Photocatalytic Reduction of Carbon Dio. Nano Energy. 13: 757-770.

[18] Y. Zhang, A. Thomas, M. Antonietti, X. Wang. 2009. Activation of Carbon Nitride Solids by Protonation: Morphology Changes. Enhanced Ionic Conductivity, and Photoconduction Experiments. J. Am. Chem. Soc. 4: 50-51.

[19] C. Huang, W. Zhang, Z. Yan, J. Gao, W. Liu, P. Tong, L. Zhang. 2015. Protonated Mesoporous Graphitic Carbon Nitride for Rapid and Highly Efficient Removal of 
Microcystins. RSC Adv. 5: 4536845375.

[20] J. Wang, D. Hao, J. Ye, N. Umezawa. 2017. Determination of Crystal Structure of Graphitic Carbon Nitride: $\mathrm{Ab}$ Initio Evolutionary Search and Experimental Validation. Chemistry of Materials. 29: 26942707.

[21] R. Niu, L. Kong, L. Zheng, H. Wang, H. Shi. 2017. Novel graphitic Carbon Nitride Nanosheets/sulfonated Poly (ether ether ketone) Acid-base Hybrid Membrane for Vanadium Redox Flow Battery. Journal of Membrane Science. 525: 220-228.

[22] G. N. B. Baroña, J. Lim, M. Choi, B. Jung. 2013. Interfacial Polymerization of Polyamidealuminosilicate SWNT Nanocomposite Membranes for Reverse Osmosis. DES. 325: 138147.

[23] X. Zhang, J. Tian, Z. Ren, W. Shi, Z. Zhang. 2016. High performance Thin-film Composite (TFC) Forward Osmosis (FO) Membrane Fabricated on Novel Hydrophilic Disulfonated Poly (Arylene Ether Sulfone) Multiblock Copolymer/Polysulfone Substrate. Journal of Membrane Science. 520: 529-539.

[24] T. Sirinupong, W. Youravong, D. Tirawat, W. J. Lau, G. S. Lai, A. F. Ismail. 2017. Synthesis and Characterization of Thin Film Composite Membranes Made of PSF-TiO2/GO Nanocomposite Substrate for Forward Osmosis Applications. Arabian Journal of Chemistry. 11: 1144-1153.

[25] D. Emadzadeh, W. J. Lau, A. F. Ismail. 2013. Synthesis of Thin
Film Nanocomposite Forward Osmosis Membrane with Enhancement in Water Flux without Sacrificing Salt Rejection. DES. 330: 90-99.

[26] B. Khorshidi, T. Thundat, D. Pernitsky, M. Sadrzadeh. 2017. Permeation Properties of Thin Film Composite Polyamide Membrane. Journal of Membrane Science. 535: 248-257.

[27] B. Jeong, E. M. V Hoek, Y. Yan, A. Subramani, X. Huang, G. Hurwitz, A. K. Ghosh, A. Jawor. 2007. Interfacial Polymerization of Thin Film Nanocomposites: A New Concept for Reverse Osmosis Membranes. J. Memb. Sci. 294: 17.

[28] G. S. Lai, W. J. Lau, P. S. Goh, A. F. Ismail, N. Yusof, Y. H. Tan. 2016. Graphene Oxide Incorporated Thin Film Nanocomposite Nanofiltration Membrane for Enhanced Salt Removal Performance. DES. 387: 14-24.

[29] M. Rezaei-dashtarzhandi, M. H. Sarrafzadeh, P. S. Goh, W. J. Lau, A. F. Ismail. 2018. Development of Novel Thin Film Nanocomposite Forward Osmosis Membranes Containing Halloysite/Graphitic Carbon Nitride Nanoparticles Towards Enhanced Desalination Performance. DES. 447: 18-28.

[30] M. R. Teixeira, M. J. Rosa, M. Nyström. 2005. The Role of Membrane Charge on Nanofiltration Performance. Journal of Membrane Science. 265: 160-166.

[31] N. Ma, J. Wei, R. Liao, C. Y. Tang, 2012. Zeolite-polyamide Thin Film Nanocomposite Membranes: Towards Enhanced Performance 
Protonated Carbon Nitride Incorporated TFC Membrane for RO Desalination 43

for Forward Osmosis. Journal of 157.

Membrane Science. 405-406: 149- 